\title{
Educational Game Design as Gateway for Operationalizing Computational Thinking Skills among Middle School Students
}

\author{
Min Lun $\mathrm{Wu}^{1}$ \\ ${ }^{1}$ Patton College of Education, Ohio University, Athens, OH, USA \\ Correspondence: Min Lun Wu, Patton College of Education, Ohio University, Athens, OH, 45701, USA. Tel: \\ 1-517-775-8897. E-mail: wum@ohio.edu
}

Received: October 30, 2017

doi:10.5539/ies.v11n4p15

\author{
Accepted: December 13, 2017 Online Published: March 28, 2018 \\ URL: https://doi.org/10.5539/ies.v11n4p15
}

\begin{abstract}
This qualitative case study reports descriptive findings of digital game-based learning involving 15 Taiwanese middle school students' use of computational thinking skills elicited through programmed activities in a game design workshop. Situated learning theory is utilized as framework to evaluate novice game designers' individual advancement in developing a designer language, mindset, and use of computational thinking skills. Three strands of findings were extrapolated from analyzing observational data, participant-generated written responses and artifacts: Understanding games as systems and how components work together in meaningful relationships in game design; Developing growing sophistication in communicating with other novice game designers using language germane to game design; Improving understanding and application of computational thinking skills through game design activities. Extended discussions on three focal cases revealed that using design pedagogy, participants operationalized computational thinking skills in design tasks. Promises and pitfalls of using game design to facilitate computational thinking skills are discussed.
\end{abstract}

Keywords: computational thinking, game design, situated learning theory, digital game-based learning (DGBL), middle school students

\section{Introduction}

In recent decades, video games have served primarily as a source of recreation with which players engage arduously in hours of play to improve playing skills and progress through different levels and games. Concurrently, researchers have researched into the potential of using games as pedagogical tools in and outside of classrooms (Denner, Werner, \& Ortiz, 2012; Gee, 2008; Lee, Martin, Denner, Coulter, Allan, Erickson, Malyn-Smith, \& Werner, 2011; Salen, 2007; Squire \& Klopfer, 2007). Collectively, the goals of game-using teachers and educational game designers are to integrate learning objectives with elements of gameplay and fun while assuring learner/players acquire concepts or knowledge useful in real world applications.

Van Eck (2006, 2015) discussed four forms of digital game-based learning (DGBL) for classroom implementation-Using teacher-designed games, student-designed games, commercially off-the-shelf (COTS) games, and gamification. The current study opts for student-designed games as vehicle for delivering DGBL and investigates how game design tools and design pedagogy combined with a researcher-developed curriculum could be leveraged to support students' emergent development of computational thinking (CT) skills. The purpose of this study lies in demonstrating that digital games can be powerful media through which CT skills-decomposition, pattern generalization and abstraction, pattern recognition, algorithm design, data analysis and visualization - can be operationalized. Studying how K-12 students develop CT skills through game design poses significant implications for educating our $21^{\text {st }}$ Century learners in the core subjects of science, technology, engineering, arts and mathematics (STEAM).

\section{Literature Review}

\subsection{Framing Computational Thinking}

In the age of participatory culture, one of the critical media literacy skills for $21^{\text {st }}$ Century learners is the ability to garner, analyze, generalize, and visualize information gleaned and gained from multiple media sources (Jenkins, Clinton, Purushotma, Robinson, \& Weigel, 2010). The constant influx of multi-modal data requires learners to use not only their conventional literacy skills but also new skills such as digital and technological literacy with the aim 
to effectively navigate the boundless world of information. With this backdrop, the researcher contends that the ability to use CT skills to critically assess and solve problems is imperative and thus demands immediate attention.

Wing (2006) posited that CT confronts the riddle of machine intelligence. What can humans do better than computers? And what can computers do better than humans? More fundamentally, CT addresses the question: "What is computable?" (Wing, 2006, p. 33). As of today, we still only know parts of the answer to such a question. Bundy (2007) posed that CT is pervasive because it enables us to confront new questions, search for new answers, formulate new hypotheses, operationalize new theories, and establish new thinking patterns. Today, CT is not a skill only computer scientists need to be adept at but everyone, it is a skill needed by all. This point is driven home by Wing's statement: "Ubiquitous computing was yesterday's dream that become today's reality; computational thinking is tomorrow's reality" (2006, p. 34). CT is changing the way we think because CT has become an integral part of our functions in everyday life.

While in the higher education arena, people can grapple with the abstract definitions of CT, the same cannot be said of the K-12 levels. Cooper, Perez, and Rainey (2010) posed several reasons for this dilemma. First, computer science does not appear within the core topics covered in high schools because it would be tough to justify a computer science course at the removal of another course. Second, computer science as an elective topic tends to be disproportionately available to those wealthy suburban schools. Furthermore, there is the paucity of K-12 computing teachers to implement a national scale computing requirement. Nor is it clear how other K-12 subject area teachers would take advantage of school children who had been trained in CT. Piaget (1964) posed the four stages of cognitive development among children. Middle school children aged around 11 are in the formal operational stage where they begin to think abstractly and are capable of deductive and logical reasoning. The researcher argues this is a critical age frame for educators to teach children CT skills. The current study addresses the gap in teaching children CT skills and conducts a workshop to assist in developing CT skills in a primarily after-school setting.

In this study, the researcher focuses on five CT skills middle school students can use in game design tasks. The word 'skill' as related to CT denotes a cognitive skill rather than a physical skill. Hence the researcher's intent was to observe participants' use of language, behaviors and think-aloud emerged from the engagement of game design activities geared toward facilitating $\mathrm{CT}$ at the locale of the workshop, and subsequently analyze observational and written data generated by participants with which operationalization of CT skills could be extrapolated.

The CT skills under examination are: First, decomposition is the ability to break down a system into constituents or deconstruct a task into procedures so that one can explain the elements of a process to another person or to a computer. Second, pattern recognition is the ability to spot commonalities or disparities that will help one make predictions or lead to shortcuts. Third, pattern generalization and abstraction is the ability to filter out information not necessary for solving problems, generalize information as necessary, and extrapolate principles/concepts from information presented. The fourth CT skill is the ability to develop step-by-step strategies for solving problems, namely algorithm design. The fifth skill is data analysis and visualization, which is defined as information abstracted in schematic form, including attributes or variables for units of information (Friendly \& Denis, 2001) or the ability to represent complex networks or systems in visual representations. The current study builds on research and practice of teaching CT (Wing, 2006, 2008) and game design pedagogy (Denner et al., 2012; Games, 2008; Lee et al., 2011; Salen, 2007; Squire, 2005) and seeks to find correlation between engagement of game design and operationalization of CT skills.

\subsection{Educational Game Design as Viable Pedagogy}

Game design is not precise science because of the subtle nature of fun (Koster, 2013). Many success stories of game designs such as Civilization series and Sim series have been repurposed for teaching while engaging players in gameplay even without interest in the educational content embedded (Squire, Devane, \& Durga, 2008). Literature supports the notion that well-designed digital games can facilitate learning (Gee, 2007, 2008; Prensky, 2001, 2006). Well-designed digital games can facilitate learning because they are designed to contextualize learning based on a set of learning principles. Principles such as immediate feedback, sandbox, customization, and adjustable difficulty motivate players to work within their regime of competence within the problem space presented by the game (Gee, 2003).

Research has identified that games can expose children to a design perspective that employs forms and practices viable both to professional and academic disciplines and can help children develop language and literacy skills (Gee, 2003; Games, 2008). The language and representations in modern video games are flexible and multimodal (incorporating images, print, audio, video, and movement) and hence Gee (2003) argues that playing video games requires multiple forms of literacy skills - digital literacy, technological literacy, and game literacy — by which 
gamers resort to when attempting to actively and critically approach game content and gameplay. Online games such as League of Legends, Defense of the Ancients, War of Warcraft, Sim City, and Civilization have graphs, statistics and audio cues to keep players informed of their character status, helping players think about the relationships between characters, and the rules and assets of the game to deploy play strategy. Considering the complexity in information uptake and thought processes involved in playing games nowadays, the researcher posits that a learner's ability to consolidate these different forms of literacy skills and think computationally to solve in-game problems is critical in predicting his/her approach and performance in game design.

Games (2008) and Salen (2007) argued that game-making is well-suited to the purpose of inducing meta-level reflection on the skills and processes that designer-players use in constructing systems. Through consistent engagement of game design activities, learners can gain fluency of a specialist language that allows them not only to talk or think about games but also to make and critique them (Games, 2008). Decision-making in game design is conducive to critical thinking. Even though game decisions may seem trivial to most others but these small decisions constitute a line of accountability - a personal accountability that may not be important to others but are important decisions because they bring immediately observable consequences to your projected identity during gameplay (Salen, 2007).

Through adopting a designer mindset and the language of game design, children as designers will learn the situated meaning of tools, roles, and representations in the context of a discourse (Gee, 1996). These novice designers would, through practice and iterative game design, become novice members of a specific community through adopting the "identity kit comprising of ways of doing, being, talking, and thinking" (Games, 2010). Therefore they are then members of a specific community - the gaming community.

\subsection{Theoretical Considerations for Game Design Pedagogy}

The foundation on which this game design study rests is the theoretical underpinnings of the situated learning theory (Lave, 1988; Lave \& Wenger, 1991). This theory poses that learning occurs in a context where the activity of learning takes place. In essence, learning is situated in a community of practice where learners share similar goals for learning. Situated leaning theory has been applied previously in technology-based learning contexts where the focus is on problem-solving skills (Cognition \& Technology Group at Vanderbilt, 1993).

In this study, the learning setting for the community of practice is the game design workshop where over time students become increasingly involved, through social interactions, with fellow novice game designers who hold certain beliefs and behaviors toward games and game design. Workshop participants learned from the game design curriculum and applied gained knowledge and skills in hands-on design tasks. Squire et al. (2008) studied the effect of using Civilization III, a historical simulation game, as a possibility space for young learners to learn world history. Their study described an approach to bridging learners' identities in and out of school through Civilization III situated within a community of practices of game experts. Following from the same vein, the current study underscores situated theories of game-based learning and argues that the learning and application of CT skills are embedded in the process of designing games.

Building upon situated learning theory, Wenger (2007) discussed the critical elements that distinguish a community of practice from others. These elements are the domain, the community, and the practice. Salen (2007) enumerated an array of knowledge and skills necessary for successful game design-system-based thinking, writing and storytelling, interactive design, iterative critical problem solving, art and aesthetics, programming, and game logic and rules (p. 305). Design pedagogy opens doors for novice learners to learn these skills and knowledge in a sandbox environment where they are encouraged to try new things and make mistakes. This environment offers a unique and low-stakes domain space different from other professionally demanding learning sites.

The researcher contends that the participants in this study constitute a unique community of practice because the environment in which they function during the workshop contains all three distinct elements depicted by Wenger (2007). The students' commitment to games is what would create a shared competence. The members of this specific community play games, talk about games, learn about game design languages and skills, and collaborate in teams. Through benevolent teamwork and shared expertise, the learners stay on task and learn from each other. These novice game designers must learn to explain and defend game design ideas, delineate design process, reflect on player interaction meta-cognitively, formulate, test, and revise hypotheses for improved design. To be a functional member in this community, they have to engage in repeated problem-solving, resource sharing, and sustained social interactions. The above traits and interaction features define the subjects in this study as members of a community of practice as they explore, investigate, and cooperate to play games, think and learn with games, and explore game design. 


\section{Method}

This study is an exploratory case study examining how a game design workshop utilizing a researcher-developed game design curriculum could operationalize middle school students' use of CT skills in design tasks. The case study approach is appropriate to be used in studying contemporary phenomenon and social interactions in a real-life context (Yin, 1994). The face-to-face game design workshop situated itself in a real-life context and took place in a computer laboratory based in a private middle school in northern Taiwan in 2011.

\subsection{Research Question}

The researcher's working hypothesis was that DGBL utilizing a design curriculum and pedagogy could support participants' application of CT skills in game design. The following research question was examined:

How could the researcher-developed game design curriculum and pedagogy operationalize middle school students' CT skills?

The research question concerns individual participant's trajectory of being enculturated into game design tasks and community. The researcher's intent lies primarily not in building causal relationships between engagement in game design and the operationalization of CT skills, rather the significance of this question lies more in debunking the processes and experiences these novice game designers would undergo via working with the three design tools.

\subsection{Participants and Procedure}

Purposeful sampling was adopted and consequently seven $7^{\text {th }}$ grade (six boys and one girl) and eight $8^{\text {th }}$ grade students (five boys and three girls) were selected out of a pool of 33 prospective applicants. Screening mechanisms included prior gaming history, current gaming habit, and interest in learning game design. Gender difference was not accounted for considering the disproportion of boys and girls who eventually applied. The phenomenon was not surprising considering gaming had been predominantly perceived as a male-oriented domain (Cassell \& Jenkins, 1998).

The 15 participants came to a school computer laboratory from 8AM to 12PM on five consecutive weekdays. They received instruction and engaged in design activities using three purpose-built game design tools in succession-Gamestar Mechanics, Lego Universe, and Microsoft Kodu. The sequencing of the three game design tools render considerations of pacing, understanding of narrative arc, game space modeling, and incremental difficulty in tasks of design. Prior to the beginning of workshop, parental permission forms describing the research were sent home with each student. Only students with returned signed consent forms were included in this study.

Instructional materials in the form of worksheets were used to collect written data and they involved the following topics: Elements of game design in goal, rule, asset, space, play mechanic, and scoring system (GRASPS); T-rex and three triceratops fable story in situating objects and relationships; game name and genre probe in assessing background knowledge; adapted CT exercise for connecting to real-life instances and problem-solving; playtest evaluation form in eliciting peer-to-peer communication and feedback for design refinement; design tool comparison questionnaires for reflection on technical and design considerations. Participants were instructed to resort to the design mnemonic GRASPS and to consider player experience during design. They were encouraged to create an imaginary player-designer dialogue by thinking exogenously like a designer when they designed games and concurrently were asked to reflect endogenously on their vicarious experience as imaginary players who would be playing the games designed by him- or herself (Games, 2010).

The main goal of the workshop was to train students to think like game designers, who look at not just the parts of a game but at the whole system of a game, allowing them to develop system thinking and eventually participate in design at a more meaningful level. The workshop consisted of a series of lessons and activities to galvanize student development of CT skills, game design language and mindset, and to induce reflection on own learning progress as novice members of the game design community.

\subsection{Data Collection and Analysis}

Data were collected from multiple sources including reflective short answer questionnaires, observational field notes, game artifacts, and student worksheets. Triangulation of data was conducted to obtain three forms of evidence-linguistic, behavioral, and artifact. Data were analyzed to support or refute claims of participants' development of CT skills operationalized through the researcher-developed curriculum and game design tools. The researcher drew on Geertz's (1973) "thick description" to strengthen analysis and enhanced the validity of this mechanism in conducting game research. All research activities were conducted by the researcher as he recorded and interpreted the succession and happenings of events.

For purpose of this study, three of the 15 student cases were highlighted with situational references to other cases 
or observational and written data. The researcher selected these three cases because they captured a spectrum of positive and negative issues encountered by all participating students in the workshop.

\section{Findings and Discussions}

The researcher conducted qualitative analysis on the data gathered from questionnaires, design worksheets, and observations and coded the data using a scheme modeling the theoretical underpinning of situated learning theory-learning is situated in a community of practice where learners share similar goals for learning (Lave \& Wenger, 1991). The coding scheme was refined after successive passes and eventually evolved into three broad schemes which described these novice game designers' differing approaches, successes and frustrations in learning game design, in relation to their emergent development of CT skills in design-related tasks. The hypothesis that DGBL using the researcher-developed curriculum and design pedagogy could facilitate participants' application of CT skills in game design was supported. The three broad schemes are:

1) Ongoing development of a designer language and mindset: Through instruction and immersion in game design tools and activities, participants became attuned to the technical terms of game design, started using design terms in communication, and steadily evolved in terms of leveraging CT skills critical to the identity kit (Gee, 2007) of a designer mindset (Games, 2008, 2010).

2) Varying developmental trajectories and individual/group dynamic: With discrepant prior gaming history, preference, and background entering the workshop, the 15 participants fared through different trajectories in the ways he/she approached and participated in individual and group-based game design activities.

3) Learning is most effective when tasks are situated in immediately relatable contexts: Participant enthusiasm, concentration on task, and the creativity of design artifacts were observed to be more prominent in scenarios when design activities were collocated with design instructions. In effect, game design activities were more effective when participants operated in immediately-relatable contexts where they applied what they learned from instruction to hands-on design tasks.

In response to the research question, findings are presented in the form of three focal cases, Kevin, Steven, and Claire (pseudonyms), and their respective developmental process as novice game designer in the workshop. Findings are discussed in relation to the three broad schemes. Three strands of evidence, linguistic, behavioral, and artifact, are discussed to substantiate the three focal cases' exploratory experience, identification/non-identification with a designer identity, and emergent application of CT skills evident in game design and related problem-solving tasks.

\subsection{Kevin the Guru and Avid Helper}

Kevin was a $7^{\text {th }}$ grader who volunteered on site during the researcher's initial visit to the classrooms. By the end of day one, the researcher was quick to note that Kevin's prior knowledge in games evidently excelled in comparison with other participating members. Through conversations, the researcher found that Kevin was habitually and actively involved in a Taiwan-based online gaming community named "Maple Story" where he extracted information related to gameplay strategy and exchanged resources with other online gamers. By midway through day three, Kevin emerged as the guru capable in independent game design and became a trustworthy design consultant for peers. With regard to linguistic development and usage of game language, Kevin was more versed than others in using terms such game genres (e.g., ACT, RPG) and describing how players could use play mechanics to achieve the win state in games. Kevin was also keen in identifying the relationship between characters (i.e., thinking computationally to decompose and recognize patterns) in the T-rex and three triceratops fable story and used the identified concept for subsequent game design (see Figure 1). Furthermore, Kevin was among the top participants who effectively completed the adapted CT exercises within a time limit, indicating his capability in thinking computationally to solve mathematical problems. 


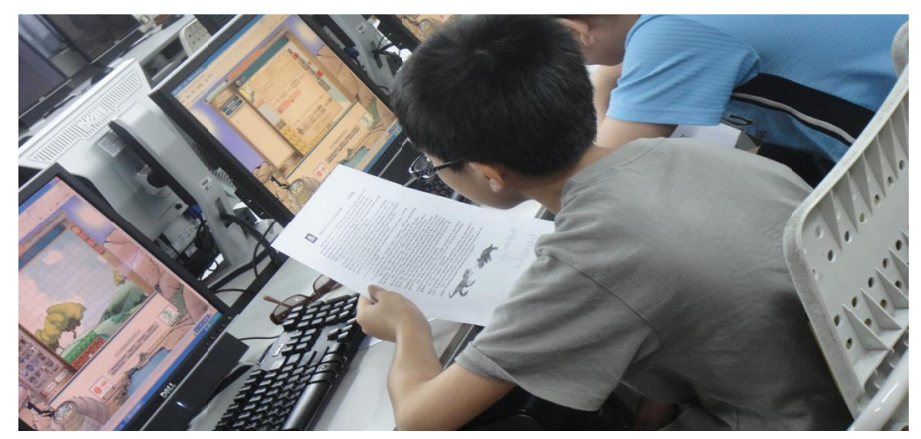

Figure 1. Kevin deciphering the fable for identification of relationship between characters

In the design tool comparison questionnaire, Kevin pinpointed the upsides and downsides of each tool. A case in point, Kevin expressed his liking of Gamestar Mechanics in that the design tool offered step-by-step instruction on learning how to play, design, and publish games. With Microsoft Kodu, Kevin pointed to the limitation of terrain creation using hand-drawn image showing that he was not able to construct a tunnel (see Figure 2).

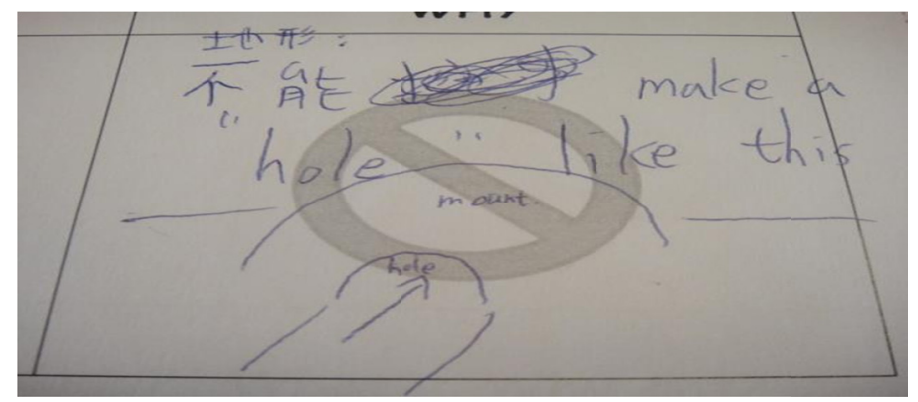

Figure 2. Limitation of terrain creation in Microsoft Kodu

A novel approach to the teaching and learning of history was proposed by Kevin where he proposed designing a massive multiplayer online role playing game (MMORPG) for history class at school based on the rationale that he wanted to "make history class more interactive and interesting". On playtest evaluation forms, Kevin was articulate in commenting on the positives and negatives in games designed by fellow participants. Remarks such as "heavily leaning towards shooting", "low variety of assets", and "you can consider adding different types of monsters" exemplified Kevin's insightful observations via playtesting. For recommendations on improving Gamestar Mechanics and Microsoft Kodu, Kevin suggested adding transition computer graphics and multi-player mode, both of which were salient features common in popular commercially produced games nowadays. Taken altogether, Kevin's written responses in the questionnaires reflected his thoughtfulness in thinking in the shoes of the players (i.e., focusing on player experience) and this thoughtfulness translated into a level of sophistication in the game artifacts he designed (i.e., adopting a designer mindset).

Online game forums mark an unorthodox venue similar with the notion of a community of practice in that the online forum affords participants who share similar special interests in a certain game the opportunities to interact with comrades and construct a knowledge base meaningful to their respective purposes for gaming. The three elements of domain, community and practice are as rich in an online game forum as in other conventional face-to-face realms for cooperative learning. It was likely due to Kevin's pre-existing outside-of-workshop exposure to online game forums that contributed to his enthusiasm and savvy in understanding games as system of elements.

Kevin's background knowledge in games also assisted his identity-taking as a novice game designer. Compared to other participants, Kevin was quick to get accustomed to the three-dimensional environment in Microsoft Kodu as he constructed an infrastructure promptly and navigated game space with ease. In both individual and group work, Kevin's design artifacts were thoughtful and reflected his in-depth understanding and application of the mnemonic GRASPS in design. In teamwork, Kevin frequently assumed the role of leader and offered advice and assistance to 
refine design. Kevin attempted to teach a $7^{\text {th }}$ grade participant to create a mountain and insert other accessorial items using basic programming and then construct relationships between the items created. This is an example where Kevin used the CT skill algorithm design to assist a fellow participant and this exemplified his behavioral development in gradually taking on a designer role and mindset.

Bartle's player type taxonomy in multi-user dungeon (MUD) games stated that players in the online environment generally take on one of four approaches in gameplay (Bartle, 1996). Killers engage in wiping out adversaries or other player characters; Socializers are intent on building relationships with other players; Explorers focus on the quests and investigations of surroundings; Achievers favor the activity of getting points or leveling up. These four player types were found not to be mutually exclusive in Yee's (2006) study on motivations to play in online games. Considering Kevin's vested interest in online games, an implication for research lies in investigating the potential relationship between the main player type or a combination of player types one adopts and how the role adoption in turn influences his/her approach in game design and design orientations.

\subsection{Steven the Zealous yet Digressive Knowledge Seeker}

Despite his relatively meager gaming background coming into the workshop, Steven became a focal case among the $8^{\text {th }}$ graders because of his enthusiasm and continuous effort in exploring game design and seeking assistance from other participants, until a workshop event offset his concentration and kept him digressed on the third day.

The researcher found that despite Steven's strong interest in gaming, his parents did not allow him to play video games at home except on weekends. Steven had relatively meager knowledge of what online games are composed of, how players interact online, and where to look for game-related resources. While these conditions did not necessarily preclude Steven from learning about game design, his sparse gaming background and lack of resources did not place him in advantage. It was likely due to the inhibition at home that Steven was observed to appear extra active during teamwork as he offered opinions during team concept mapping and volunteered to design the game space using Gamestar Mechanics. Steven was doing all these work on his own volition and he progressed equally well compared to other participants. That remained the case with Steven's early involvement in design related activities, until entering the latter part of day three of the workshop.

When participants were introduced to the second design tool, Lego Universe, excitement was apparent. The researcher assumed participants were provoked based on three reasons. Firstly, the game was a stand-alone application which required them to complete independent installation to launch into play and this meant they got to keep playing this MMORPG at home after the workshop. Secondly, the look, feel and gameplay of Lego Universe were friendly and familiar because the tool shared commonalities with popular MMORPGs some of the participants were playing then. Thirdly, since the game design tool Lego Universe was distributed as a stand-alone application, each participant received a complimentary copy and to these youngsters the game was perceived initially more as an incentive rather than a formal design tool to learn with. Steven in particular, fell within the third assumption.

Steven appeared to be caught up by the excitement that he would get to play a long-awaited MMORPG at home, and he seemed jumpy and unable to concentrate on the design tasks assigned on day three. During teamwork on designing a Gamestar Mechanics game, Steven appeared out of focus as he scattered enemy avatars around the game space aimlessly (see Figure 3). For Steven, day three marked the watershed between his early proactive role as a knowledge seeker and latter role switch becoming resistant to reengage and adopt a designer mindset that required him to think systemically in balancing the components of GRASPS in design.

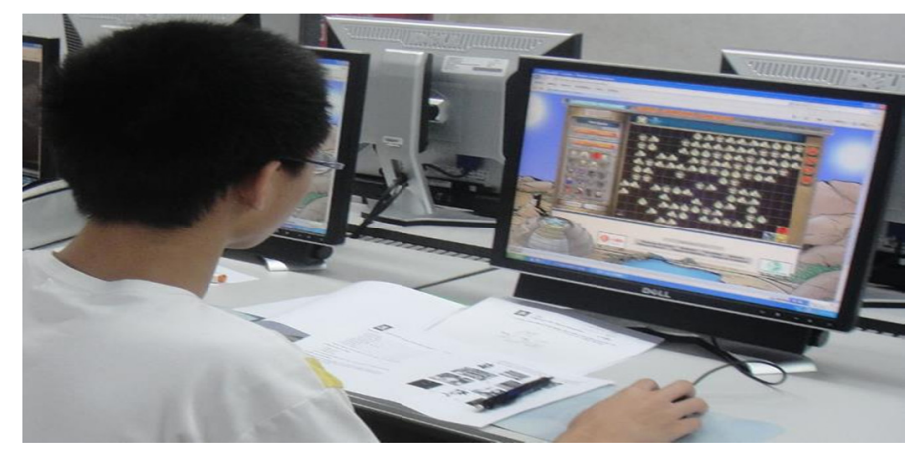

Figure 3. Steven appearing out of focus and mapping enemies sporadically around game space 
Regarding written responses on worksheets, Steven struggled with providing thoughtful answers for most prompts. He left spaces blank and a great proportion of his responses was short and shallow (e.g., good plot; good game; good to be able to make games; I don't know), indicating his lack of involvement in thinking critically to assess own gameplay and design experience using Gamestar Mechanics and Microsoft Kodu. Evidence related to Steven's understanding and application of CT skills in design tasks was thin.

Interestingly, the use of Lego Universe for Steven did not seem to influence his design perspective. Three assumptions could be attributed to Steven's dissipated focus and to explain his digressive behaviors in the latter parts of workshop. First, the novelty effect of playing a MMORPG may have taken Steven over in the sense that Steven was intently absorbed in gameplay as a player and he was not able to assume the role and perspective of a game designer accordingly. Unlike other participants who managed to treat Lego Universe as a transition tool following the researcher's instruction, playing Lego Universe for Steven caused an identity conflict. Second, Steven's lack of prior gaming background precluded him from pinpointing features of Lego Universe potentially useful for his own game design. Third, the researcher did not provide sufficient scaffolding for inexperienced participants such as Steven to help them immerse in gameplay and concurrently learn to translate desirable game features into actual design.

\subsection{Claire the Capable Loner}

Claire was an $8^{\text {th }}$ grader female student entering the workshop who left strong first impressions on the researcher during initial classroom visits. As the researcher promoted the workshop, Claire looked intent and raised a series of questions with ranging relevance. Consequently, Claire became one of the four girls who enrolled in the workshop.

Much like Kevin, Claire was also regularly involved in a Taiwan-based online game forum but a different one named "Heaven 2". On multiple occasions when the researcher conversed with Claire about how she approached gameplay and game design, topics pertaining to Heaven 2 would surface. This phenomenon indicated the impact of this online game on Claire's perceptions toward what the game she designed should emulate. The online gaming community exerted influence on Claire in two ways: First, Claire came into the workshop already equipped with some background knowledge about popular game genres and this knowledge helped her ease into design tasks; Second, through sharing information and resources in online game forums, Claire was thus aware of the notion that the games she designed would eventually be played by others. Claire mentioned in conversational exchanges her desire to let other friends of hers play the games she designed on Gamestar Mechanics and she seemed earnest about receiving feedback from peers, as indicated by her written response on game tool worksheets. This means when Claire designed her own games, she took player experience into account and was in the position to incorporate elements that would facilitate better play experience. By accounting for player experience, Claire leveraged CT skills such as pattern recognition, algorithm design, data analysis and visualization toward a more well-rounded game design (see Figure 4). Being familiar with the popular game genre MMORPG, and concurrently exposed to online game forum positively affected how Claire adopted a designer mindset and took on design tasks throughout the workshop sessions.

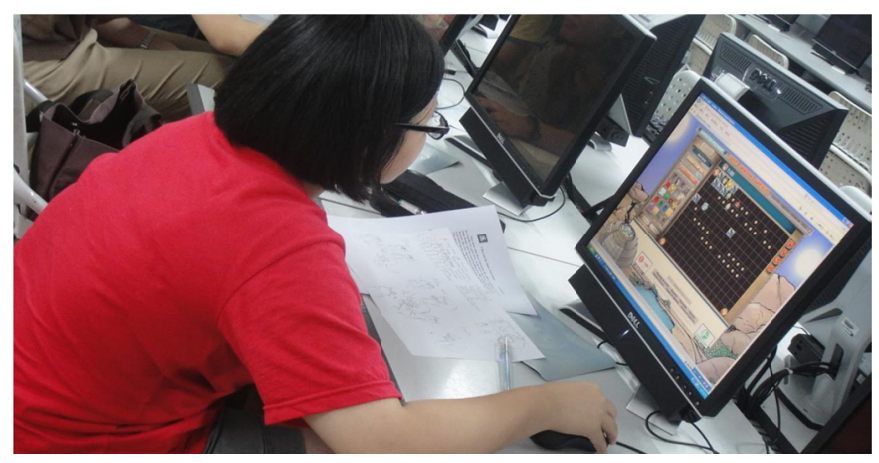

Figure 4. Claire concentrating on game design based off of her concept map

Putting Claire's worksheet responses under scrutiny, it became apparent that Claire was insightful in pointing out the strengths of design tools. For instance, Claire enumerated several comments on the Gamestar Mechanics questionnaire, indicating the fun elements as feeling accomplished having to complete quests to propel the flow of the storyline and playing the games designed by others inspired creativity and motive in revising her own. Claire 
was innovative in proposing the design of a RPG for math class as she used CT skills to decompose her imaginary game setting into relational components. Setting for Claire's proposed RPG entailed math instructor being the infamous final boss character; examinations, homework, make-up assignment, corporal punishment being the villains and player character being the brave hero/heroine on a quest to defeat the antagonists.

When it came to providing feedback on playtest evaluation form, Claire was considerate in picking the target game apart and commented critically while referencing to the elements of GRASPS. Unlike other participants, Claire did not only give generic comments such as "excellent" or "very fun" but explained what she would do to improve design and gameplay experience. The game artifacts designed by Claire demonstrated a reasonable level of sophistication and she reflected on her own design experience when asked to playtest and evaluates the games designed by others. For example, Claire commented on the element of play mechanic by pointing out that the target game required strategic movement to reach the win state and was thus challenging. Claire also commented on the element of assets, indicating the need for adding more health points to the player avatar. All in all, Claire displayed exceptional understanding of the researcher's instruction and the information presented in instructional materials. She produced evidence related to her linguistic and behavioral development in thinking computationally, as observed during workshop and documented on written materials.

Another premise based on which Claire was selected as a focal case was that she seemed to deliberately distance herself from the other female participants. Though she was a classmate with the other two $8^{\text {th }}$ grade participants, most of the time Claire was observed to be working on her game design and worksheets independently, by choice, even when admonished by the researcher that cooperation was encouraged. Claire persisted as a lone designer throughout the duration of five days as she fared through design-related tasks with relative ease and moderate to high concentration, while all the time keeping to herself. Unlike Kevin and most other participants, Claire was content working on her own. When working in groups, it was observed that Claire did not tune herself in with the other three female members during game plot planning. Despite Claire's lackluster involvement in teamwork, she displayed a competent level of verbal proficiency in using game design language and the game artifacts created by Claire were overall richer in content and more structured paralleling the elements of GRASPS compared to the games other participants created.

The fact that Claire chose to be a loner contradicted with the researcher's first impressions of her being actively vocal in raising questions during researcher's classroom visit. Possibilities for Claire's introverted behaviors could be personal disposition so that she felt inhibited by teamwork, or she was holding back from voicing her opinions because of the predominantly male presence.

Claire's solitaire approach to game design, while not necessarily atypical, raises important issues related to how gender-based differences in attitudes toward game design may impact how females develop CT skills and other technology-related skills. Sociologist Turkle's (1988) study showed that males and females approach the computer with different attitudes. Males see computers as machines as a challenge to be mastered and overcome by demonstrating new techniques to dominate the machine, namely an extension of males' desire for showcasing personal and physical power. For males, computers are objects of quest and conquer. On the other hand, females tend to approach computers as "soft", indicating the attitude toward the machine as tactile, artistic, and communicative. Consequently females will attempt to work with the computer in a cooperative manner to achieve goals. For females, computers are collaborative partners and objects with which to communicate.

Gender-based difference was discussed in Huff and Cooper's (1987) study in examining gender bias in software design. They found that when software programmers were told to design education software for girls, the software produced were very different in tone, nature, and make-up than ones designed by programmers told to design for boys or not told of target gender. The programs produced for girls were strictly learning tools with little value for entertainment. This meant the programmers did not see it fit for girls to engage in play style of learning. Also intriguing was the assumption that when designers were not given a specific gender, they naturally assumed they were designing for male users. Another study in gender-based software design evidenced along the line of gender difference. Kafi's (1993) study asked $4^{\text {th }}$ graders to design a game that would teach fractions and the findings showed the themes in games designed by boys and girls were quite different. The games designed by boys embodied goal-oriented gameplay where players had to retrieve something through exploration. The boys' games resembled with commercial titles they were familiar with.

On the contrary, the games designed by girls were activity-oriented in that gameplay centered on the learning activity and how well players could perform it. The girls' games were without objects to be retrieved or won back and instead focused on the performance of the target activity. While these findings were based in a different time and context, it is noteworthy that the gender difference still played out in a modern day setting. One of such being 
the researcher-conducted game design workshop Kevin, Steven, Claire and the other 12 participants attended.

Based on the researcher's observations and field notes, the boys in the workshop preferred playing sports, shooting, and action games during recess whereas girls preferred role-playing and puzzle games. These tendencies stemmed in part from personal preference, prior experience with games, and from popular media influence. Taken altogether the tendencies portrayed an array of human activities along the line of stereotypes and gender differences. The influence is mirrored though the difference in games designed by boys and girls. Adding confirming evidence to prior research, the 11 boys in this study were inclined to incorporate elements of shooting, chasing, and collecting points in designing games on Gamestar Mechanics and Microsoft Kodu. The four girls on the other hand tended to organize the game space in the form of a maze and placed premium on following a storyline or solving puzzles during gameplay. In summary, boys and girls were seeking different forms of fun in gameplay and in turn the games produced by different gender reflected that definition of fun, gameplay, and game goal. It is not clear whether by pursuing different forms of fun, play experience or game goal in game design, boys and girls are engaging in different ways to think computationally. But it is safe to assume that by adopting different approaches to game design, boys and girls may, under the influence of multimedia and prior gaming history, prioritize the usage of certain CT skills over others, thus contributing to differences in their end product of game design. This assumption remains untested and future research should tap into gender-engendered differences in using CT skills in game design.

On the design tool comparison worksheet, the 15 participants also provided a collective thread of interesting comments on how Gamestar Mechanics and Microsoft Kodu allowed or disallowed them from engaging in a type or goal of design. One $8^{\text {th }}$ grader Hank (pseudonym) was a sports fan and his passion for sports carried over to games. He was observed to be constantly playing either billiard or basketball games during breaks. On a worksheet, Hank commented that he could not use Gamestar Mechanics to design a sports game because the tool does not allow for multiplayer play. One $7^{\text {th }}$ grader Paul (pseudonym) also pinpointed a limitation of using Gamestar Mechanics in that the background themes available were static and the player avatar was mostly constrained to a limited set of actions - chase, jump, and shoot. Regarding Microsoft Kodu, a $7^{\text {th }}$ grade girl Olivia (pseudonym) realized through play and design that she became more immersed in the environment because of the graphical affordance of three-dimensional objects and landscape. However, she did feel dizzy at times when she navigated in the three-dimensional construct. The usually critical Paul criticized on the low number of selectable avatars in Microsoft Kodu. On a positive note, Paul saw Microsoft Kodu fitting as a tool for teaching geography because through autonomous landscape construction, students could be taught the features of different geographical terrains. One $8^{\text {th }}$ grade girl Michelle (pseudonym) wrote that she would use Microsoft Kodu to teach biology by designing a game that models the interdependent relationships of food chain among sea creatures. With varying degree, the written comments generated by the 15 participants were thoughtful and reflective of their personal preference, prior experience with games, and ongoing progress in terms applying the concept of GRASPS in their own design. Analysis of textual data also revealed that as the participants were instructed to assume both the roles of a novice game designer and a player, they were required to switch between imagined identities while attempting to think reflectively about their design choices made as derived from using different game design tools.

The interpretive descriptions of these three focal cases' varying trajectory through which he/she experienced successes, frustrations, and ongoing development into a novice game designer were illuminative of how these youngsters' prior gaming background, work-style, and personal preferences interplayed with the cognitive and practice demands imposed on them throughout the five-day game design workshop. The participants pointed out on the worksheets that the three design tools denoted both affordances and constraints when it came to possibility for design. The researcher observed and documented the operationalization of the five CT skills evident in participant engagement in conceptualization activities, design tool worksheets, playtest evaluations, and hands-on game design.

\section{Conclusion}

For these 15 participants, does game design translate into a way of thinking about the world and in what specific context does this form of thinking apply? Salen (2007) suggested that if we could see evidence of such thinking at work, we could "have a more clear idea of what forms of learning and modes of literacy are general and specific to games and be able to take advantage of this understanding in the creation of both new games and learning environments" (p. 308). The current study tapped into one such form of design-based thinking, namely CT, and investigated how CT could be utilized in the applied context of game design.

Overall the 15 participants developed their understanding and usage of design language and mindset. CT skills were fostered through a series of design and reflection activities. Considering the three focal participants' differing 
background and preference in games, it is not surprising that these novice designers evolved at different points of a spectrum. The linguistic, behavioral, and artifact references evidenced the three focal cases' struggles and successes in learning game design and their tendencies reflected a range of challenges confronted by the other 12 participants. Three strands of learning emerged from examining the written data generated by these 15 participants: Understanding games as systems and how components work together in meaningful relationships in game design; Developing growing sophistication in communicating with other novice game designers using language germane to game design; Improving understanding and application of CT skills through game design activities.

However, it begs the question as to whether the game design activities in the workshop promoted participants' CT skills. The counter hypothesis was that CT is perhaps already applied in daily life situations such as instructing on how to disassemble a piece of furniture into parts (decomposition), writing up a recipe and giving directions (algorithm design), looking for patterns in stock prices (pattern recognition), using daily planner to represent a week's tasks in terms of days and hours (pattern abstraction), or delivering a presentation using infographics (data visualization). Hence it is important to note that the purpose of utilizing game design to facilitate CT does not preclude other life experiences from contributing to the ongoing usage and development of CT skills. Rather, game design pedagogy represents an opportunity to learn and an unorthodox approach to support the activation and operationalization of CT skills.

\subsection{Limitations}

There are several limitations in this study. First, inter-rater reliability was not procured in analyzing textual data and generating coding schemes since this study was conducted by a single researcher who acted also as the main instructor of the game design workshop. The limitation poses the risk of researcher bias and subjectivity during data analysis and subsequent interpretations.

The second limitation is that the Internet firewall and security protocol stipulated by the school prevented participants from saving some of the games they designed during workshop sessions. While this limitation did not deter the youngsters from participation, their momentum was thwarted. The necessity of a large scale buy-in among staff, technology coordinators, and administrators was underscored not only for the sake of streamlining logistics, but for the understanding that the field of DGBL represented a wellspring of opportunities for administrators, teachers and students to take advantage of and learn from.

\subsection{Implications for Future Research: Moving Onward with DGBL}

Digital games have the power of shaping culture, inspiring ideas, and cultivating creativity. A designer who is equipped with the know-how to deploy formal research could channel new currents into the ocean of possibility in conducting theory-and-research informed designs. Game design research is a relatively new field of study. Wright and Laurel (2003) repeatedly emphasized the importance of research within the discipline of game design. In investigating the issue of how to do game design research, El-Nasr (2006) noted that experimental games could be based on different "design research methods ranging from artistic exploration (borrowing from artistic design methods), iterative prototyping and testing (borrowing from software engineering design methods), and rigorous ethnography and focus group studies (borrowing from social science and software design research methods)" (p. 5). This current study is a crossover extension of the latter two design research methods in that the participants were taught the play-centric design loop and engaged in rapid digital prototyping, and iterations of design based on feedback provided by the instructor and peers.

This study is a qualitative study involving participation of a focus group of 15 middle school students interested in game design. The analysis done based on the textual and observational data revealed the procedural knowledge and cognitive processes through which our young game designers approached and learned from game design. The findings alluded to potential in using design pedagogy for the operationalization of CT skills. However, confounding variables such as participants' pre-existing knowledge in gaming and involvement in game communities might well factored into how these novice designers approached the task of game design. Controlling for these confounds in future research would strengthen methodology and the effectiveness of game design pedagogy. Using design pedagogy to facilitate CT skills and produce far-transfer effects for formal learning of core academic subjects remain directions worthy of further research.

The researcher argues a qualitative perspective adds an important layer to studying the operationalization of CT skills through educational game design as it provides a lens/narrative through which we could better understand the rich processes and nuances on how youngsters play to learn and develop into a novice game designer. At the same time the researcher acknowledges the value, need and importance of developing a set of quantifiable outcome measure for assessing CT skills in game design. When a quantifiable measure of CT skills comes to 
fruition, future research should use mixed method research design to collect both quantitative and qualitative data for triangulation and to provide more sustainable empirical evidence. Another direction for future research would be to investigate currently existing curricula in the core subjects of STEAM to develop optimal sets of evaluation standards on how $\mathrm{CT}$ can be fostered and assessed.

The findings of this study showed that DGBL incorporating game design pedagogy has the potential to operationalize CT skills in design-related contexts. Findings also indicated that different game design tools offered varying affordances and constraints in training different novice game designers to think computationally while acting on design. The construct of $\mathrm{CT}$ presented in this study is less than exhaustive considering that this research focused only on a specific subset of students learning game design. The question lingers as to what does optimization of CT in other non-game related contexts looks like. The study of CT is a work in progress and is at its embryonic stage and the researcher urges game designers, educators, researchers, and other stakeholders in education to investigate the issue of how and with what tools can we use to help $21^{\text {st }}$ Century learners not just learn to use and think with technology, but to create and critique with technology. In effect we play games for fun and simultaneously play to learn. Games present such a venue with which young learners explore while embarking on a thought-provoking journey of design.

\section{References}

Barab, S. A., Sadler, T. D., Heiselt, C., \& Hickey, D. (2007). Relating narrative, inquiry, and inscriptions: supporting consequential play. Journal of Science Education and Technology, 16(1), 59-82. https://doi.org/10.1007/s10956-006-9033-3

Bartle, R. (1996). Hearts, clubs, diamonds, spades: Players who suit MUDs. Journal of MUD research, 1(1), 19.

Bundy, A. (2007). Computational thinking is pervasive. Journal of Scientific and Practical Computing, 1(2), 67-69.

Cassell, J., \& Jenkins, H. (1998). From Barbie to Mortal Kombat: Gender and computer games. Cambridge, MA: MIT Press.

Chatham, R. E. (2007). Games for training. Communications of the ACM, 50(7), 36-43. https://doi.org/10.1145/1272516.1272537

Cognition \& Technology Group at Vanderbilt. (1993). Anchored instruction and situated cognition revisited. Educational Technology, 33(3), 52-70.

Connolly, T. M., Stansfield, M., \& Hainey, T. (2011). An alternate reality game for language learning: ARGuing for multilingual motivation. Computers \& Education, 57, 1389-1415. https://doi.org/10.1016/j.compedu.2011.01.009

Cooper, S, Perez, L. C., \& Rainey, D. (2010). K-12 computational learning. Communications of the ACM, 53(11), 27-29. https://doi.org/10.1145/1839676.1839686

Denner, J., Werner, L., \& Ortiz, E. (2012). Computer games created by middle school girls: Can they be used to measure understanding of computer science concepts? Computers \& Education, 58(1), 240-249. https://doi.org/10.1016/j.compedu.2011.08.006

El-Nasr, M. S. (2006). Game design research. Journal of Game Design, 2(1), 5-9.

Friendly, M., \& Denis, D. J. (2001). Milestones in the history of thematic cartography, statistical graphics, and data visualization. Retrieved from http://www.datavis.ca/milestones

Fullerton, T. (2008). Game design workshop: A playcentric approach to creating innovative games. MA: Morgan Kaufmann

Games, I. A. (2008). Three Dialogs: a framework for the analysis and assessment of twenty-first-century literacy practices, and its use in the context of game design within Gamestar Mechanic. E-Learning, 5(4). 396-417. https://doi.org/10.2304/elea.2008.5.4.396

Games, I. A. (2010). Gamestar Mechanic: Learning a Designer Mindset through Communicational Competence with the Language of Games. Learning, Technology and Media, 35(1), 31-52. https://doi.org/10.1080/17439880903567774

Gee, J. P. (1996). Social linguistics and literacies: Ideology in discourses. New York: Routledge.

Gee, J. P. (2003). What Video Games Have to Teach Us about Learning and Literacy. New York: Palgrave Macmillan. 
Gee, J. P. (2007). Good video games + good learning: Collected essays on video games, learning and literacy. New York: Peter Lang. https://doi.org/10.3726/978-1-4539-1162-4

Gee, J. P. (2008). What video games have to teach us about learning and literacy, revised and updated. Basingstoke: Palgrave Macmillan.

Geertz, C. (1973). Thick description: Toward an interpretive theory of culture. The interpretation of cultures. New York: Basic Books.

Huff, C., \& Cooper, J. (1987). Sex bias in education software: The effect of designers' stereotypes on the software they design. Journal of Applied Social Psychology, 17(6). https://doi.org/10.1111/j.1559-1816.1987.tb00328.x

Jenkins, H., Clinton, K., Purushotma, R., Robinson, A. J., \& Weigel, M. (2010). Confronting the Challenges of Participatory Culture: Media Education for the 21st Century. Chicago, IL: John D. and Catherine T. MacArthur Foundation Reports on Digital Media and Learning; 2006.

Kafi, Y. B. (1993). Minds in play: Computer game design as a context for children's learning (Doctoral Dissertation, Harvard Graduate School of Education, Cambridge, MA).

Kelly, H., Howell, K., Glinert, E., Holding, L., Swain, C., Burrowbridge, A., \& Roper, M. (2007). How to build serious games. Communications of the ACM, 50(7), 44-50. https://doi.org/10.1145/1272516.1272538

Kordemsky, B. A. (1972). The Moscow puzzles: 359 mathematical recreations. NY: Charles Scriboner's Sons.

Koster, R. (2013). Theory of fun for game design. Paraglyph.

Lave, J. (1988). Cognition in Practice: Mind, mathematics, and culture in everyday life. Cambridge, UK: Cambridge University Press. https://doi.org/10.1017/CBO9780511609268

Lave, J., \& Wenger, E. (1991). Situated learning: Legitimate peripheral participation. Cambridge, UK: Cambridge University Press. https://doi.org/10.1017/CBO9780511815355

Lee, I., Martin, F., Denner, J., Coulter, B., Allan, W., Erickson, J., ... \& Werner, L. (2011). Computational thinking for youth in practice. Acm Inroads, 2(1), 32-37. https://doi.org/10.1145/1929887.1929902

Mayo, M. J. (2007). Games for science and engineering education. Communications of the ACM, 50(7), 30-35. https://doi.org/10.1145/1272516.1272536

Michael, D., \& Chen, S. (2006). Serious games: Games that educate, train, and inform. MA: Thomson Course Technology.

Papastergiou, M. (2009). Digital game-based learning in high school computer science education: Impact on educational effectiveness and student motivation. Journal of Computers \& Education, 52, 1-12. https://doi.org/10.1016/j.compedu.2008.06.004

Piaget, J. (1964). Part 1: Cognitive development in children: Piaget development and learning. Journal of research in science teaching, 2(3), 176-186. https://doi.org/10.1002/tea.3660020306

Prensky, M. (2001). Digital game-based learning. New York: McGraw-Hill.

Prensky, M. (2006). Don't Bother Me, Mom, I'm Learning!: How Computer and Video Games Are Preparing Your Kids for 21st Century Success and How You Can Help! Minnesota: Paragon House.

Rankin, Y., Gold, R., \& Gooch, B. (2006). 3D role-playing games as language learning tools. Eurographics, 25(3), 1-6.

Rankin, Y., McNeal, M., Shute, M. W., \& Gooch, B. (2008). User centered game design: Evaluating massive multiplayer online role playing games for second language acquisition. Sandbox Proceedings of the 2008 ACM SIGGRAPH symposium on Video games (pp. 43-50). https://doi.org/10.1145/1401843.1401851

Salen, K. (2007). Gaming literacies: A game design study in action. Journal of Multimedia and Hypermedia, 16(3), 301-322.

Squire, K. (2005). Changing the game: What happens when video games enter the classroom? Innovate, 1, 6 .

Squire, K., \& Klopfer, E. (2007). Augmented reality simulations on handheld computers. Journal of the Learning Sciences, 16(3), 371-413. https://doi.org/10.1080/10508400701413435

Squire, K., DeVane, B., \& Durga, S. (2008). Designing centers of expertise for academic learning through video games. Theory into Practice, 47(2), 240-251. https://doi.org/10.1080/00405840802153973 
Tate, R., Haritatos, J., \& Cole, S. (2009). HopeLab's approach to Re-mission. International Journal of Learning and Media, l(1), 29-35. https://doi.org/10.1162/ijlm.2009.0003

Technology Group at Vanderbilt. (1993). Anchored instruction and situated cognition revisited. Educational Technology, 33(3), 52-70.

Turkle, S. (1988). Computational reticence: Why women fear the intimate machine. Technology and Women's Voices: Keeping in Touch. Ed. C. Kramarae, London: Routledge.

Van Eck, R. (2006). Digital game-based learning: It's not just the digital natives who are restless. Educause Review, 41(2), 16.

Van Eck, R. N. (2015). Digital game-based learning: still restless after all these years. Educause Review, 50(6), $13-28$.

Wenger, E. (2007). Communities of practice. A brief introduction. Communities of practice. Retrieved from $\mathrm{http}: / /$ wenger-trayner.com/introduction-to-communities-of-practice/

Wing, J. M. (2006). Computational thinking. Communications of the ACM, 49(3), 33-35. Wing, J. M. (2008). https://doi.org/10.1145/1118178.1118215

Yee, N. (2006). Motivations for play in online games. Cyber Psychology \& behavior, 9(6), 772-775. https://doi.org/10.1089/cpb.2006.9.772

Yin, R. K. (1994). Case study research: Design and methods. Sage publications.

\section{Copyrights}

Copyright for this article is retained by the author(s), with first publication rights granted to the journal.

This is an open-access article distributed under the terms and conditions of the Creative Commons Attribution license (http://creativecommons.org/licenses/by/4.0/). 